\title{
METODOLOGIAS ATIVAS DE APRENDIZAGEM NA FORMAÇÃO DOCENTE EM HISTÓRIA
}

METHODOLOGIES LEARNING LIVE IN TRAINING TEACHERS IN HISTORY

\author{
DEBALD, Blasius Silvano ${ }^{1}$ \\ DEBALD, Fátima Regina Bergonsi, ${ }^{2}$
}

\section{RESUMO}

A formação de docentes de História é permeada pelas Diretrizes Curriculares Nacionais e amparada pela legislação vigente. A opção pelas Metodologias Ativas de Aprendizagem na formação docente está relacionada ao contexto de transformações e mudanças vivenciadas na educação superior. $\mathrm{O}$ estudo analisou os percursos docentes de História na Faculdade Comunitária União das Américas de Foz do Iguaçu-PR quanto a aplicação de inovações no processo de construção de aprendizagens.Aquestão norteadora investigou se os docentes conseguem trabalhar a História utilizando as Metodologias Ativas de Aprendizagem. Em termos metodológicos o estudo assumiu a perspectiva ligada aos princípios da História Oral pelas suas características na compreensão de fenômenos contemporâneos ou que ainda estão em curso.Destacamos como resultados a predisposição dos docentes de reverem suas práticas e inovarem na ação pedagógica. E como conclusões, identificamos a satisfação dos docentes atuando na metodologia que foca na aprendizagem, estimulando a autonomia e o protagonismo estudantil.

Palavras-Chave: Metodologias Ativas - Aprendizagem - História -Formação Docente

\section{ABSTRACT}

The formation of History professors is permeated by the Brazilian National Curriculum Guidelines (Diretrizes Curriculares Nacionais) and supported by law. The option for the Active Learning Methodologies

in teachereducationisrelatedtothecontextofexperiencedtransformationsandchanges in higher education. The study examined the History Professors at Community College Union of the Americas at Foz do Iguaçu-PR as the application of innovations in the learning process of construction. The main question investigated whether professors can work History using the Active Learning Methodologies. Methodologically the study assumed the perspective linked to the principles of oral history for its features in the understanding of contemporary phenomena or are still ongoing. We high light as resultsthewillingnessofprofessorstoreviewtheirpracticesandinnovate in the pedagogical action. And as conclusions, we identify the satisfaction of teachers working in the methodology that focuses on learning, encouraging autonomy and student leadership.

Keywords: Active Learning Methodologies, Professor Training, History

\footnotetext{
${ }^{1}$ Doutor em Educação. Coordenador e Professor da Faculdade Comunitária União das Américas UNIAMÉRICA, Avenida Garibaldi, 2100, casa 166, Jardim Lancaster, CEP 85869-470, Foz do Iguaçu-PR. E-mail: blasius@uniamerica.br.

${ }^{2}$ Mestre em Educação. Professora da Faculdade Comunitária União das Américas - UNIAMÉRICA, Avenida Garibaldi, 2100, casa 166, Jardim Lancaster, CEP 85869-470, Foz do Iguaçu-PR. E-mail: fatima@uniamerica.br.
}

Criar Educação, Criciúma, v. 6, ํ1, julho/novembro 2016.- PPGE - UNESC 


\section{INTRODUÇÃO}

As inovações tecnológicas e metodológicas integram os processos formativos dos docentes nos cursos de História na segunda década do século XXI. A finalidade do estudo analisou os percursos docentes de História na Faculdade Comunitária União das Américas de Foz do Iguaçu-PR quanto a aplicação de inovações no processo de construção de aprendizagens. A pesquisa tem sua relevância, pois as inovações vivenciadas no curso e na Instituição são inovadores, mediante a aplicação das Metodologias Ativas de Aprendizagem e Estudos Baseados em Projetos, tornando o estudante protagonista da construção de conhecimentos.

As mudanças nos processos educativos no curso de História foram motivadas pela presença de práticas de memorização e reprodução, aliadas ao desinteresse dos estudantes. Com as inovações metodológicas em curso na Instituição, identificamos maior dinamismo por parte dos estudantes, além de promover estudo em parceria e aprofundamento teórico.

A opção pela inovação na formação docente de História é motivada pelas transformações que estão ocorrendo na educação superior e que impactam diretamente na sala de aula. Rever práticas reprodutivistas e investir em modelos inovadores de educação tornaram-se elementos desafiadores no desenvolvimento profissional docente.

Em termos metodológicos, o estudo proposto assume a perspectiva ligada aos princípios da História Oral pelas características que essa perspectiva assume na compreensão de fenômenos contemporâneos ou que ainda estão em curso. A utilização da História Oral como método de pesquisa vem se acentuando nas últimas décadas. A sua propagação funda-se, principalmente, nas contribuições de Thompson (1992); Meihy (2005); Ferreira e Amado (2001); Delgado (2006); Meihy e Holanda (2007) e Montenegro (2010). A opção de utilizar a História Oral favorece o pesquisador em seu intento de compreender o ser humano na centralidade da investigação.

As etapas do estudo constituíram-se: a) Observação - acompanhamento dos docentes nas salas de aula para compreender as novas posturas para atuação e de que forma a História era trabalhada com os estudantes; b) Entrevistas com os docentes - nas quais procuramos identificar dificuldades, desafios e motivações Criar Educação, Criciúma, v. 6, nº1, julho/novembro 2016.- PPGE - UNESC 
para aderir ao projeto de inovação implantado na Instituição; c) Análise do material utilizado em sala de aula - desde o Ambiente de Aprendizagem no qual são disponibilizados os materiais de estudos, até o novo papel docente para atuar na Sala de Aula Invertida; d) Descrição das entrevistas; e) Análise e discussão das entrevistas - identificando elementos que serviram para compreender o processo de inovação; e) Confrontamento com a bibliografia relativa às Metodologias Ativas de Aprendizagem. Por se tratar de uma temática recente, a literatura é rica de estudos, mas caso de aplicação no Brasil, em nível institucional, é pioneiro.

\section{METODOLOGIAS ATIVAS DE APRENDIZAGEM NA FORMAÇÃO DOCENTE EM HISTÓRIA}

A História é um campo de conhecimento que congrega variedade de correntes e a formação de novos docentes requer cuidados, pois os cursos tem responsabilidade com a formação qualificada, motivada pela crise vivenciada na educação básica brasileira. Rompe-se com um modelo de formação inicial de docentes que se estruturava na formação teórica - primeira parte do curso e, posteriormente a formação prática - estágios. O campo de atuação docente não era vivenciado desde o começo do curso, criando falsa ilusão de que fazer História não era ser Professor de História.

Para transformar a formação inicial no curso de História, a Faculdade Comunitária União das Américas, de Foz do Iguaçu, Paraná, discutiu e após longo período de formação dos docentes, promoveu mudanças no currículo e na metodologia. $O$ elemento central da mudança reside na postura dos docentes, não mais centros do processo educativo, mas mediadores e orientadores da aprendizagem.

Com as mudanças no cenário docente, o planejamento semestral e de sala de aula promoveu a reestruturação da carreira, mediante novos desafios, com a reinvenção da práxis pedagógica. Pensar a sala de aula não como espaço de exposição, mas de discussão, problematização e aprofundamento temático, oportunizando participação e autonomia do estudante estava entre os desafios. E como o docente se posicionou perante as transformações em curso e de que forma se adaptou ou incorporou o novo?

Criar Educação, Criciúma, v. 6, №1, julho/novembro 2016.- PPGE - UNESC 
CRIAR EDUCACẼ̃O

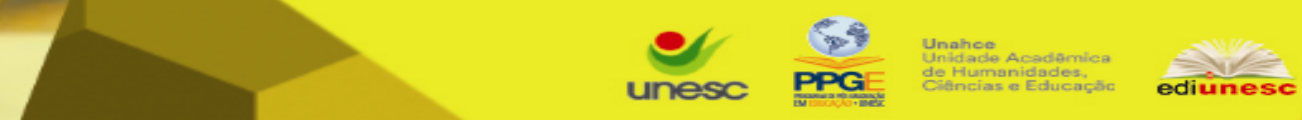

A primeira tentativa do docente é colocar o novo no velho para ajustar e dar continuidade as mesmices. Não há compreensão e nem disposição de romper com o planejamento e atuação em sala de aula. Requer novo aprendizado e, sobretudo dispor-se a aprender diferente o que sempre fez. A etapa de desestabilizar a docência foi rompida mediante a formação de quase dois anos, em cursos e vivências do modelo, praticando os processos de mudança. Referente ao contexto de introdução de inovações no campo educacional, Garcia (1980, p. 11) alerta que:

[...] necessitam de um clima de maior tolerância e de possibilidade de criação para que possam representar algo significativo para a educação [...] parece quase claro que propostas viáveis de inovação educacional exigem que os educadores e a comunidade corram o risco de ensaios e erros, avanços e retrocessos, para encontrarem formulações que atendam efetivamente às necessidades sentidas.

A inovação construída na Faculdade Comunitária União das Américas teve o apoio da Mantenedora, Direção, Corpo Docente, Equipe Administrativa e da maioria dos estudantes matriculados. Dito dessa forma parece que não tivemos resistências nos processos de implementação do modelo pedagógico. As resistências foram travadas por parte de estudantes que solicitaram transferência para outras Instituições e os docentes que não se adaptaram à proposta foram se desligando com o passar o tempo. A implantação de mudanças educacionais no ensino superior é um processo lento e requer cautela para não ferir a legislação, além de quebrar paradigmas quanto a estrutura secular universitária.

Especificamente no curso de História, objeto do estudo, acompanhamos onze docentes (três do sexo masculino e oito do feminino), durante o período de transição e implantação do novo modelo, baseado em projetos e nas metodologias ativas de aprendizagem. Observamos os docentes em sala de aula - mediante prévia autorização - como também realizamos entrevistas dialogadas, nas quais relatavam dificuldades e facilidades enfrentadas com a nova metodologia adotada pela Instituição.

O estudo elencou resultados interessantes como a adesão dos estudantes à proposta, sem muitas resistências. O currículo, organizado por temáticas e não mais de forma linear, surpreendeu num primeiro momento, mas após o impacto inicial tornou-se um desafio. Os docentes tiveram que rever o planejamento semestral, pois o modelo pedagógico previa estudos prévios pelos estudantes. Assim, o material Criar Educação, Criciúma, v. 6, no1, julho/novembro 2016.- PPGE - UNESC 


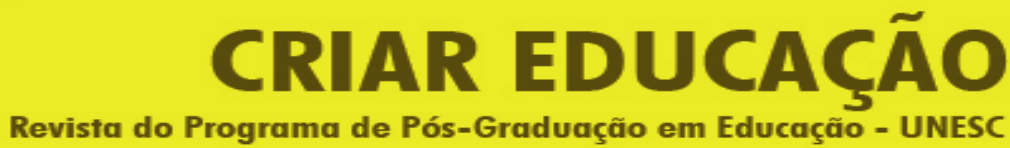

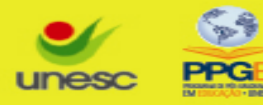

precisava ser disponibilizado com antecedência no Ambiente de Aprendizagem para acesso, leitura e estudo por parte do estudante.

Outro aspecto significativo foi a disposição dos docentes de aderirem ao modelo, mesmo com mais de 20, 30 anos de docência. E quando foram indagados sobre 0 porquê da mudança, responderam que estavam cansados das mesmices. Também identificamos que os docentes tiveram nova postura frente a produção do conhecimento. Antes, centralizavam as ações de sala de aula e agora, como mediadores, o protagonismo passou para os estudantes.

$\mathrm{Na}$ minha tese, publicada em 2016, analisei a carreira docente no ensino superior, sua compreensão e constituição, em contextos de ensino privado, cujas mudanças e transformações são mais rápidas em virtude do modelo de educação praticada (DEBALD, 2016).A migração da Instituição de privada para comunitária, mexeu na organicidade e, como consequência a docência reestruturou-se para colocar em prática um novo modelo educacional. Sacristán (2006, p. 396) afirma que a profissionalidade "é o específico na ação docente, isto é, o conjunto de atuações, destrezas, conhecimentos, atitudes e valores necessários ao exercício da profissão de professor."

A modificação das práticas só foi possível mediante investimentos na formação dos docentes e continuam participando de processos formativos mensais com concentrações de uma semana no começo do ano letivo e em julho. O material utilizado pelos estudantes no pré-estudo para as aulas é elaborado pelos docentes, composto pela temática, objetivos, texto base, vídeo explicativo e uma atividade. Em sala de aula o docente propõe um desafio articulador dos estudos da semana, conectando a temática, contextualizando-a e problematizando-a.

Fava (2016) enfatizou a necessidade de provocar novas situações no âmbito da sala de aula, incentivando os estudantes

a expor novas situações problemas de situações já vivenciadas em que se aplicam os conteúdos, procedimentos, habilidades, competências desenvolvidas. Poderá provocar um debate com toda a turma quanto à aplicabilidade dos conteúdos, procedimentos, atividades. Por fim, integrar os três tempos didáticos, orientando os estudantes a ler os materiais, realizar as atividades de aprofundamento no pós-aula (FAVA, 2016, p. 252).

Nas entrevistas identificamos que os docentes, no começo estavam com receio quanto as inovações metodológicas, mas na medida em que tiveram contato prático, Criar Educação, Criciúma, v. 6, nº1, julho/novembro 2016.- PPGE - UNESC 


\section{CRIAR EDUCAČ̃̃̃O}

Revista do Programa de Pós-Graduação em Educação - UNESC

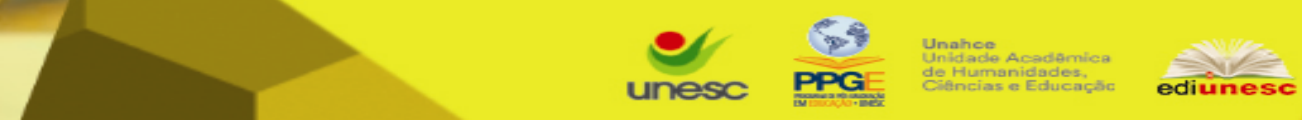

as barreiras foram rompidas. O elemento prático das aulas e a introdução das Metodologias Ativas de Aprendizagem, a resolução de problemas reais diagnosticados na comunidade, atribuiu significado à História. $\mathrm{O}$ envolvimento e o comprometimento na produção do conhecimento em parceria - docentes com estudantes - foi fator de mudança. Estuda-se para aprender e não para fazer provas. Tardiff e Lessard (2009) ao final da obra O ofício do professor - história, perspectivas e desafios internacionais, na qual analisam diversos cenários educacionais que estão em mudança, afirmaram que:

a novidade no campo educacional associa-se ao contexto de aceleração da transformação, tanto da sociedade quanto da cultura, o que torna a função da escola certamente tão importante quanto foi outrora, e até mais, porque ela atinge todos os membros de uma geração e por mais tempo do que outrora, porém mais arriscada e difícil para os docentes, porque os materiais de construção do trabalho são menos garantidos do que antes(TARDIFF; LESSARD, 2009, p. 277).

Em outras palavras, as mudanças educacionais em curso na segunda década do século XXI exigirão dos docentes mais reflexões e estudos para acompanhar e modificar as práticas pedagógicas. A sala de aula está em mutação, empurrada pela sociedade cada vez mais virtual e tecnológica, requerendo-se docentes capacitados para atuar em cenários inovadores. A ação docente está se transformando e é preciso formação para auxiliar na construção de aprendizagens.

Quando confrontamos as entrevistas dos docentes com a bibliografia, identificamos que o discurso não é livresco, mas provém da vivência no modelo. E a naturalidade com que os docentes falam das mudanças e transformações contribuem para entender que ocorre produção de aprendizagens, pois ao final de cada semestre letivo os estudantes apresentam soluções para os problemas diagnosticados. Tal postura auxilia na compreensão por que estudar certos temas e de que forma podem ser aplicados na vida em sociedade.

Estamos vivenciando nova fase de aprendizagens históricas, na qual os estudantes são os protagonistas e construtores de conhecimento. Um conhecimento que não está preso a dogmas ou currículos seculares, mas que promove mudanças que tendem a formar profissionais mais comprometidos com a realidade e se preocupem com os problemas da sociedade. Com isso não defendemos a educação utilitária, mas contextualizada e ancorada no aprender fazendo. Conforme Morin (2000, p. 54) 


\section{CRIAR EDUCAC̃̃̃}

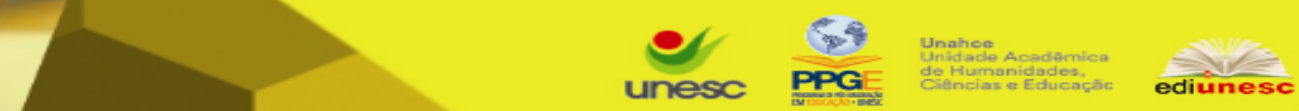

o aprendizado da vida deve dar consciência de que a "verdadeira vida", para usar a expressão de RIMBAUD, não existe tanto nas necessidades utilitárias - à quais ninguém consegue escapar -, mas na plenitude de si e na qualidade poética da existência, porque viver exige, de cada um, lucidez e compreensão ao mesmo tempo, e, mais amplamente, a mobilização de todas as aptidões humanas.

Em relação as etapas do estudo trouxeram contribuições significativas para compreender o posicionamento dos docentes frente ao contexto de transformação vivenciado pela Instituição Comunitária e de que forma está impactando na trajetória profissional. Acrescenta-se a predisposição dos docentes do curso de História na promoção das mudanças curriculares e metodológicas no espaço da sala de aula.

I - Observação. Acompanhamos as atividades letivas durante um ano e meio e a partir das observações percebemos que os docentes não apresentavam resistências ao modelo e estão plenamente adaptados. Consideraram importantes os momentos de formação, organizados em MBA (Gestão da Aprendizagem), no qual aplicam a metodologia. Os docentes novos apresentaram algumas dificuldades em relação a tecnologia e funcionamento do Ambiente de Aprendizagem.A adaptação dos docentes ao espaço da sala de aula contribuiu para a autonomia e protagonismo estudantil, gerando novas posturas de atuação e trabalho da História.

II - Entrevistas com os docentes. Entrevistamos onze docentes que atuaram nocurso durante o período de um ano e meio. A entrevista foi dialogada, na qual o docente relatava dificuldades e facilidades na nova metodologia adotada pela Instituição. Do total de entrevistados, nove docentes afirmaram que gostavam da nova metodologia, mais prazerosa, pois incentivava a autonomia e a construção de aprendizagens, além de motivar o estudante a ler mais e se apropriar de forma mais profunda dos conhecimentos.

Os docentes também destacaram a mudança da atuação, mais próxima da mediação do que transmissão de conhecimentos, valorizando a experiência e os saberes referente a temática. Conforme o relato dos docentes, a metodologia respeita o tempo de aprendizagem de cada estudante, assim como favorece 0 aprofundamento.

As entrevistas evidenciam que os docentes se sentem ambientados com a nova metodologia, favorecidos pela preparação que tiveram ao longo de quase dois anos, além do apoio Institucional. Na opinião dos docentes, os estudantes leem mais, Criar Educação, Criciúma, v. 6, o1, julho/novembro 2016.- PPGE - UNESC 


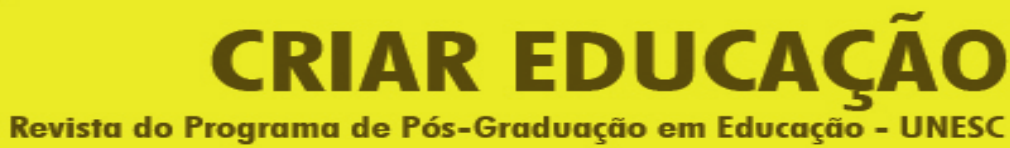

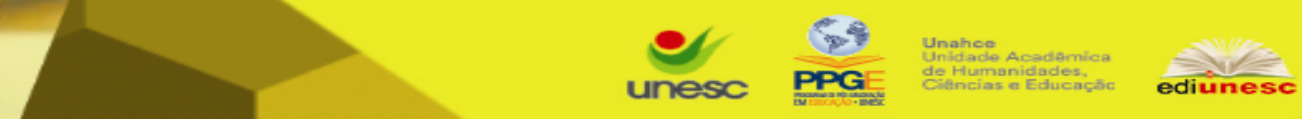

pesquisam mais e tem argumentos mais sólidos, fundamentados e com base em autores. A escrita tornou-se mais articulada e crítica.

III - Análisedo material utilizado em sala de aula.O estudo fez uma análise do Ambiente de Aprendizagem no qual são disponibilizados os materiais de estudos, quanto ao acesso e facilidade na localização das pastas e arquivos. O Ambiente é bem organizado, de fácil acesso para o estudante (basta entrar na página da Instituição com o logan e senha). Há também um tutorial com orientações e parte das atividades o estudante poderá realizar no Ambiente de Aprendizagem.

A estrutura organizacional do currículo - temáticas, objetivos, textos, vídeos, atividades e exercícios tiveram influência no papel docente e sua atuação na Sala de Aula Invertida. Agora, o estudante vem para a sala de aula com conhecimentos prévios do conteúdo, favorecendo o debate e o aprofundamento. É possível trabalhar de forma mais densa os conhecimentos.

O material disponibilizado aos estudantes é extraído de livros da Biblioteca Digital ou dentro do limite permitido digitalizados a partir de obras físicas. Os vídeos são retirados do youtube ou produzidos pelos próprios docentes. As atividades e exercícios tem conexão com a realidade, aplicabilidade com a temática em estudo, elaboradas pelos docentes. Em sala de aula os estudantes são desafiados mediante a resolução de problemas que articulam o estudo prévio, a discussão e o aprofundamento ocorrido em sala, conectado com a realidade social. É forte no modelo a aproximação da educação superior com a comunidade.

IV -Análise e discussão das entrevistas. A transcrição e análise das entrevistas foram realizadas pelos pesquisadores que acompanharam os docentes ao longo do período de estudos, servindo para compreender o processo de inovação e até que ponto o modelo tinha ou não aceitação.

Os docentes acompanham a postagem do material, o tempo de acesso e de estudo dos estudantes e dão feedback da produção individual. Os desafios em grupos realizados em sala de aula são discutidos e debatidos com intervenções, aprofundamentos e considerações dos docentes. Os desafios são propostos a partir de contextos reais e associados aos estudos da semana e do Projeto Integrador.

O docente faz breve contextualização e após os grupos iniciam a discussão para resolução do problema. Na sequência organiza-se o plenário para compreensão e 
CRIAR EDUCACẼ̃O

apropriação coletiva do conhecimento, momento em que os docentes participam com considerações e aprofundamentos.

Os desafios são práticos e requerem domínio teórico do estudante (leitura prévia) para sua resolução, além de refletir e problematizar sobre a temática em questão.

\section{V -Confrontamento com a bibliografia relativa às Metodologias Ativas de}

Aprendizagem. Por se tratar de uma temática recente, a literatura é rica de estudos, mas casos de aplicação no Brasil, em nível institucional, o da Instituição Comunitária é pioneiro.

Há estudos em que docentes ou cursos tentaram experiências similares. Contudo, uma Instituição organizada em sua totalidade, tanto estruturalmente, quanto pedagogicamente, a Faculdade Comunitária União das Américas pode ser considerada como a primeira que ousou em mexer na organização da educação superior.

O processo é lento, mas como em educação as inovações tem ritmos diferenciados, a experiência da Instituição de Foz do Iguaçu não foge à regra. Percebeu-se otimismo por parte dos docentes e a sala de aula contagia pela alegria, pelo comprometimento e vontade em aprender.

Estudar passou a ser algo prazeroso. O índice de faltas é baixíssimo e o desempenho dos estudantes melhorou significativamente. Estudantes que repetiam várias vezes as disciplinas no modelo anterior tem outro comportamento, mais participativos e realizados. O índice de evasão também diminuiu e a aprendizagem tornou-se significativa. Estuda-se para aprender, mas fazendo.

\section{CONSIDERAÇÕES FINAIS}

O estudo concluiu que os docentes são receptivos às inovações, mesmo que em um primeiro momento se sintam inseguros. Contudo, ao se apropriarem do modelo e participarem da formação continuada, vivenciando na prática, percebem que é um desafio da carreira docente e estão dispostos a encará-lo. O modelo requer maior planejamento e organização, mas o contato direto com o estudante e o feedback instantâneo diminuem a desistência e aumenta o interesse pelos estudos. Por fim, a experiência dos docentes de História da Faculdade União das Américas serve como oportunidade para introduzir mudanças na educação superior, rompendo com a Criar Educação, Criciúma, v. 6, nº1, julho/novembro 2016.- PPGE - UNESC 


\section{CRIAR EDUCAÇÃO}

Revista do Programa de Pós-Graduação em Educação - UNESC

reprodução e a memorização. Ao mesmo tempo o estudante deixa de estudar para as provas e passa a aprender com propriedade e profundidade.

Os docentes são receptivos às inovações, pois a vivência cotidiana exige maior dinamismo e engajamento. Auxilia o domínio tecnológico e a menor rigidez na disposição do espaço físico. O modelo pedagógico mexeu na estrutura física, mas sobretudo o diferencial está na forma como o processo de aprendizagem é organizado, favorecendo a autonomia e o desenvolvimento profissional e pessoal.

Rompeu-se com a ideia de que a aprendizagem é homogênea. O protagonismo ocorre no modelo educacional, pois o estudante tornou-se sujeito do seu processo de aprender. Ao promover o protagonismo estudantil, à docência passou a ter novo olhar, mais dinâmico e participativo, contribuindo para a construção de aprendizagens mais significativas. $O$ espaço da sala de aula se transformou, 0 docente inovou e os estudantes aprendem fazendo, rompendo com a dicotomia entre teoria e prática, comum da estrutura curricular dos cursos tradicionais. 


\section{CRIAR EDUCAÇÃO}

Revista do Programa de Pós-Graduação em Educação - UNESC

\section{REFERÊNCIA}

DEBALD, BLASIUS SILVANO. Docentes reféns da educação: Trajetórias e desenvolvimento profissional docentes em faculdades privadas do Extremo Oeste do Paraná - Brasil. Saarbrücken: Novas Edições Acadêmicas, 2016. v. 200. 180p.

FERREIRA, M. de M.; AMADO, J. Usos e abusos da História Oral. 8. ed. Rio de Janeiro: Editora FGV, 2006.

GARCIA, Walter E. (Org.). Inovação em educação no Brasil: problemas e perspectiva.Cortez: São Paulo: Autores Associados, 1980. (Coleção Educação Contemporânea).

MEIHY, J. C. S. B. Manual de história oral. São Paulo, Loyola, 2005.

MEIHY, José Carlos Sebe Bom; HOLANDA, Fabíola. História Oral, como fazer como pensar. São Paulo: Contexto, 2010.

MORIN, Edgar. Ciência com consciência. 4. ed.Rio de Janeiro: Bertrand Brasil, 2000.

SACRISTÁN, Gimeno. Profissionalidade Docente.[Verbete]. In:Enciclopédia de Pedagogia Universitária, v. 2. Brasília-DF: INEP/RIES, 2006.

THOMPSON, P. A voz do passado: História Oral. 2. ed. Tradução de Lólio Lourenço de Oliveira. São Paulo: Paz e Terra, 1998. 